Cao Rubian, Chen Lizhen*, Wang Jianlong and Wang Luting

\title{
The crystal structure of acetoximium $1^{\prime}$-hydroxy- $1 H, 1 H^{\prime}-5,5^{\prime}$-bitetrazole-1-olate monohydrate, $\mathrm{C}_{5} \mathrm{H}_{11} \mathrm{~N}_{9} \mathrm{O}_{4}$
}

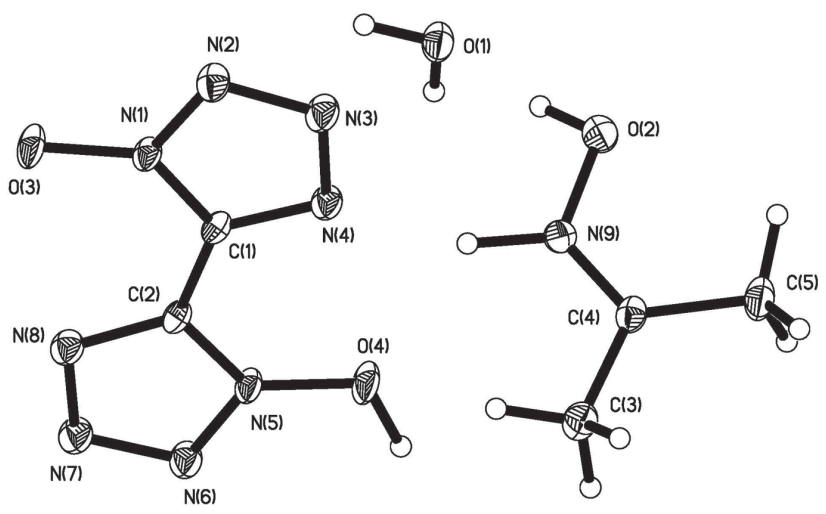

https://doi.org/10.1515/ncrs-2020-0140

Received March 13, 2020; accepted April 8, 2020; available online May 13, 2020

$$
\begin{aligned}
& \text { Abstract } \\
& \mathrm{C}_{5} \mathrm{H}_{11} \mathrm{~N}_{9} \mathrm{O}_{4}, \quad \text { monoclinic, } P 2_{1} / \mathrm{c} \quad(\text { no. } 14), \quad a=7.4259(5) \AA, \\
& b=6.6115(5) \AA, \quad c=21.9579(14) \AA, \quad \beta=93.073(2)^{\circ}, \\
& V=1076.50(13) \AA^{3}, Z=4, R_{\mathrm{gt}}(F)=0.0545, \quad w R_{\text {ref }}\left(F^{2}\right)=0.1234, \\
& T=170 \mathrm{~K} .
\end{aligned}
$$

\section{CCDC no.: 1995581}

The asymmetric unit of the title crystal structure is shown in the figure. Table 1 contains crystallographic data and Table 2 contains the list of the atoms including atomic coordinates and displacement parameters.

\section{Source of material}

An amount of $4.0 \mathrm{~g}$ of dihydroxylammonium 5,5'-bistetrazole1,1'-diolate (TKX-50) was added into the mixed solution

\section{*Corresponding author: Chen Lizhen, School of Chemical} Engineering and Technology, North University of China, Taiyuan 030051, Shanxi Province, P.R. China, e-mail: Chen17555@163.com. https://orcid.org/0000-0003-3605-4142

Cao Rubian and Wang Jianlong: School of Chemical Engineering and Technology, North University of China, Taiyuan 030051, Shanxi Province, P.R. China. https://orcid.org/0000-0001-7854-6108 (C. Rubian)

Wang Luting: Research Institute of Gansu Yinguang Chemical Industry Group Baiyin China, Baiyin 730900, Gansu Province, P.R. China
Table 1: Data collection and handling.

\begin{tabular}{ll}
\hline Crystal: & Colourless block \\
Size: & $0.15 \times 0.11 \times 0.08 \mathrm{~mm}$ \\
Wavelength: & Mo $K \alpha$ radiation $(0.71073 \AA)$ \\
$\mu:$ & $0.14 \mathrm{~mm}^{-1}$ \\
Diffractometer, scan mode: & D8 VENTURE, $\varphi$ and $\omega$ \\
$\theta_{\text {max }}$, completeness: & $26.3^{\circ},>99 \%$ \\
$N(h k l)_{\text {measured }}, N(h k l)_{\text {unique }}, R_{\text {int }}:$ & $10747,2181,0.083$ \\
Criterion for $I_{\text {obs }}, N(h k)_{\text {gt }}:$ & $I_{\text {obs }}>2 \sigma\left(I_{\text {obs }}\right), 1375$ \\
$N(\text { param })_{\text {refined }}:$ & 186 \\
Programs: & CrysAlis \\
& Diamo $[1]$, SHELX [2, 3], \\
\hline
\end{tabular}

Table 2: Fractional atomic coordinates and isotropic or equivalent isotropic displacement parameters $\left(\AA^{2}\right)$.

\begin{tabular}{lrrrr}
\hline Atom & $\boldsymbol{x}$ & $\boldsymbol{y}$ & $\boldsymbol{z}$ & $\boldsymbol{U}_{\text {iso }}{ }^{*} \boldsymbol{U}_{\text {eq }}$ \\
\hline C1 & $0.4678(4)$ & $0.6962(4)$ & $0.56104(13)$ & $0.0223(7)$ \\
C2 & $0.3537(4)$ & $0.7525(4)$ & $0.50891(13)$ & $0.0212(7)$ \\
C3 & $0.0270(4)$ & $0.8860(4)$ & $0.69939(15)$ & $0.0311(8)$ \\
H3A & 0.1253 & 0.9148 & 0.6726 & $0.047^{*}$ \\
H3B & 0.0422 & 0.9684 & 0.7364 & $0.047^{*}$ \\
H3C & -0.0887 & 0.9185 & 0.6781 & $0.047^{*}$ \\
C4 & $0.0303(4)$ & $0.6696(5)$ & $0.71606(13)$ & $0.0240(7)$ \\
C5 & $-0.0812(4)$ & $0.5872(5)$ & $0.76410(15)$ & $0.0349(8)$ \\
H5A & -0.2047 & 0.5658 & 0.7473 & $0.052^{*}$ \\
H5B & -0.0824 & 0.6831 & 0.7981 & $0.052^{*}$ \\
H5C & -0.0304 & 0.4581 & 0.7787 & $0.052^{*}$ \\
H1A & $0.169(5)$ & $0.171(6)$ & $0.5809(18)$ & $0.058(13)^{\star}$ \\
H1B & $0.353(5)$ & $0.185(5)$ & $0.5877(17)$ & $0.050(12)^{\star}$ \\
N1 & $0.6478(3)$ & $0.6824(4)$ & $0.56229(11)$ & $0.0226(6)$ \\
N2 & $0.7105(3)$ & $0.6261(4)$ & $0.61801(11)$ & $0.0275(6)$ \\
N3 & $0.5677(3)$ & $0.6063(4)$ & $0.65030(12)$ & $0.0297(7)$ \\
N4 & $0.4165(3)$ & $0.6487(4)$ & $0.61626(11)$ & $0.0254(6)$ \\
N5 & $0.1736(3)$ & $0.7569(4)$ & $0.50839(11)$ & $0.0239(6)$ \\
N6 & $0.1059(3)$ & $0.8152(4)$ & $0.45375(11)$ & $0.0290(6)$ \\
N7 & $0.2454(3)$ & $0.8460(4)$ & $0.42073(12)$ & $0.0297(6)$ \\
N8 & $0.4007(3)$ & $0.8085(4)$ & $0.45372(11)$ & $0.0265(6)$ \\
N9 & $0.1312(3)$ & $0.5542(4)$ & $0.68651(12)$ & $0.0254(6)$ \\
H9 & $0.205(4)$ & $0.601(5)$ & $0.6563(13)$ & $0.050(11)^{*}$ \\
O1 & $0.2621(3)$ & $0.1638(3)$ & $0.60785(11)$ & $0.0307(6)$ \\
O2 & $0.1442(3)$ & $0.3512(3)$ & $0.69916(10)$ & $0.0331(6)$ \\
H2 & $0.188(5)$ & $0.291(6)$ & $0.6664(14)$ & $0.084(16)^{*}$ \\
O3 & $0.7553(3)$ & $0.7118(3)$ & $0.51674(9)$ & $0.0324(6)$ \\
O4 & $0.0703(3)$ & $0.7072(4)$ & $0.55419(10)$ & $0.0349(6)$ \\
H4 & $-0.051(3)$ & $0.711(7)$ & $0.542(2)$ & $0.102(17)^{*}$ \\
\hline & & & &
\end{tabular}

This work is licensed under the Creative Commons Attribution 4.0 
containing $50 \mathrm{~mL}$ water, $7.5 \mathrm{~mL}$ acetic acid and $4 \mathrm{~mL}$ acetone below $42{ }^{\circ} \mathrm{C}$. The reaction mixture was kept at $42{ }^{\circ} \mathrm{C}$ for $2 \mathrm{~h}$. After the reaction, the reaction liquid was moved to the wildmouth bottle while it was hot, and the cap was closed tightly. After standing for $36 \mathrm{~h}$, crystals of the title compound were obtained.

\section{Experimental details}

All hydrogen atoms were identified in difference Fourier syntheses. The $\mathrm{O}-\mathrm{H}$ bond lengths were constrained to $0.87 \AA$ for the hydrogen atoms of the heterocyclic ring. The $\mathrm{C}-\mathrm{H}$ bond, $\mathrm{N}-\mathrm{H}$ bond and $\mathrm{O}-\mathrm{H}$ bond lengths were constrained to $0.98 \AA$, $0.90 \AA, 0.84 \AA$ for the hydrogen atoms of acetoximium.

\section{Comment}

TKX-50 was synthesized as a new energetic material with high energy and low sensitivity by Fischer et al. in 2012 [5, 6]. The spheroidization of energetic materials is an important way to increase energy and reduce sensitivity [7]. Solvents such as acetic acid, formic acid, acetone and water are used for TKX-50 crystallization $[8,9]$. The title compound was obtained from the crystallization of TKX-50 in acetone, acetic acid and water. The title compound was crystallized to determine it's structure by means of X-ray diffraction. The crystal structure of the title compound was analyzed and refined using the SHELXL program [1-4].

As shown in the figure, the title compound has similar heterocyclic rings structure to TKX-50. The asymmetric unit of the title compound contains one acetoximium cation, one $1^{\prime}$-hydroxy-1H,1 $1 \mathrm{H}^{\prime}$-5,5'-bitetrazole-1-olate anion and one water molecule. The heterocyclic rings in the organic anion are planar and the dihedral angle of the two tetrazole rings is $1.4^{\circ}$. The oxygen atom of N-1 and hydroxyl group of N-5 are almost coplanar with the heterocyclic ring. All bond lengths and angles are in the expected ranges.

Acknowledgements: We thank the Center of Testing and Analysis, Shanghai Institute, for support.

\section{References}

1. Oxford Diffraction Ltd: CrysAlis ${ }^{\mathrm{PRO}}$. Oxford Diffraction Ltd, Abingdon, Oxfordshire, England (2006).

2. Sheldrick, G. M.: SHELXT - Integrated space-group and crystal-structure determination. Acta Crystallogr. A71 (2015) 3-8.

3. Sheldrick, G. M.: Crystal structure refinement with SHELXL. Acta Crystallogr. C71 (2015) 3-8.

4. Brandenburg, K.: DIAMOND. Visual Crystal Structure Information System. Ver. 4.0. Crystal Impact, Bonn, Germany (2015).

5. Fischer, N.; Fischer, D.; Klapötke, T. M.; Piercey, G.; Stierstorfer, J.: The synthesis and characterization of dihydroxylammonium 5,5'-bistetrazole-1,1'-diolate. J. Mater. Chem. 22 (2012) 20418-20422.

6. Fischer, N.; Klapötke, T. M.; Reimann, M.; Stierstorfer, J.: Nitrogen-rich salts of $1 H, 1^{\prime} H-5,5^{\prime}$-bitetrazole-1, $1^{\prime}$-diol: energetic materials with high thermal stability. Eur. J. Inorg. Chem. 12 (2013) 2167-2180.

7. Zhu, Y. F.; Lu, Y. W.; Gao, B.; Guo, C. P.; Yang, G. C.: Synthesis, characterization, and sensitivity of a CL-20/PNCB spherical composite for security. Materials 11 (2018) 1130.

8. Zhang, C. Y.; Jin, S. H.; Chen, S. S.; Zhang, Y.; Qin, L.; Wei, X. C.; Shu, Q. H.: Solubilities of dihydroxylammonium 5,5'bistetrazole-1,1'-diolate in various pure solvents at temperatures between 293.15 and 323.15 K. J. Chem. Eng. Data 61 (2016) 1873-1875.

9. Li, D.; Cao, D. L.; Chen, L. Z.; Wang, J. L.; Jiang, Z. M.; Ma, X.: Solubility of dihydroxylammonium $5,5^{\prime}$-bistetrazole-1,1'-diolate in (formic acid, water) and their binary solvents from $298.15 \mathrm{~K}$ to $333.15 \mathrm{~K}$ at $101.1 \mathrm{kPa}$. J. Chem. Thermodyn. 128 (2019) 10-18. 